\title{
A Case of Stump Carcinoma with Incisional Site Metastasis
}

\author{
${ }^{1}$ Mridu Sinha, ${ }^{2}$ Ruchee Khandelwal
}

\begin{abstract}
An abdominal wall incisional metastasis from an internal malignancy is rare. In developing countries, carcinoma cervix is the most common genital malignancy in women, cutaneous involvement is rare.
\end{abstract}

Keywords: Incisional site metastasis, Cervical stump carcinoma.

How to cite this article: Sinha M, Khandelwal R. A Case of Stump Carcinoma with Incisional Site Metastasis. J South Asian Feder Menopause Soc 2014;2(2):95-96.

\section{Source of support: Nil}

\section{Conflict of interest: None}

\section{INTRODUCTION}

An abdominal wall incision metastasis from an internal malignant neoplasm is a rare finding and often considered as ominous prognostic sign with short survival. Here we report a case of stump carcinoma with incisional site metastasis. This was a biopsy-proven metastasis from the patient's primary stump carcinoma.

A 36-year-old Para1 posthysterectomized lady presented in our gynecology outpatient department with chief complaints of progressively increasing pain and swelling at lower abdominal incision site for last 4 months. She had no complains of bleeding per vaginum (pv), discharge pv, bladder or bowel involvement. She underwent supracervical hysterectomy for chronic pelvic pain 6 months back outside in a private nursing home (papers NA). Her previous cycles were regular and there was no history of postcoital bleeding.

On examination, she was of average built and her vitals were stable. Perabdomen-a hard tender mass, approximately $3 \times 2.5 \mathrm{~cm}$ felt over low transverse suprapubic scar. Perspeculum examination-both cervical

\footnotetext{
${ }^{1,2}$ Assistant Professor

${ }^{1}$ Department of Obstetrics and Gynecology, Shri Rammurti Smarak Institute of Medical Sciences, Bareilly, Uttar Pradesh India

2Department of Pathology, Shri Rammurti Smarak Institute of Medical Sciences, Bareilly, Uttar Pradesh, India

Corresponding Author: Mridu Sinha, Assistant Professor Department of Obstetrics and Gynecology, Shri Rammurti Smarak Institute of Medical Sciences, Bareilly, Uttar Pradesh, India Phone: 09897608050, e-mail: sinhamridu72@gmail.com
}

lips visible, smooth with no growth over it. On bimanual examination-partial left-over cervix was felt continuous with a firm-to-hard growth at stump, approximately $3 \times$ $2 \mathrm{~cm}$, separately from incisional site mass. Right parametrium was free whereas left parametrium had indurated feel. Per-rectal examination also confirmed the findings. After dilating the os, endocervical biopsy was taken and sent for HPE, which came out to be positive for squamous cell carcinoma.

Ultrasonography showed cervical stump $(3.1 \times 2.0$ $\mathrm{cm})$ with altered echotexture, and a hypoechoic lesion $(3.3 \times 2.5 \mathrm{~cm})$ involving anterior abdominal wall (rectus muscle at scar site) with slow flow noted in it (?) Scar granuloma (Fig. 1).

Contrast-enhanced computed tomography showed an irregular mass $(4.7 \times 3.9 \times 3.5 \mathrm{~cm})$ at pelvic region
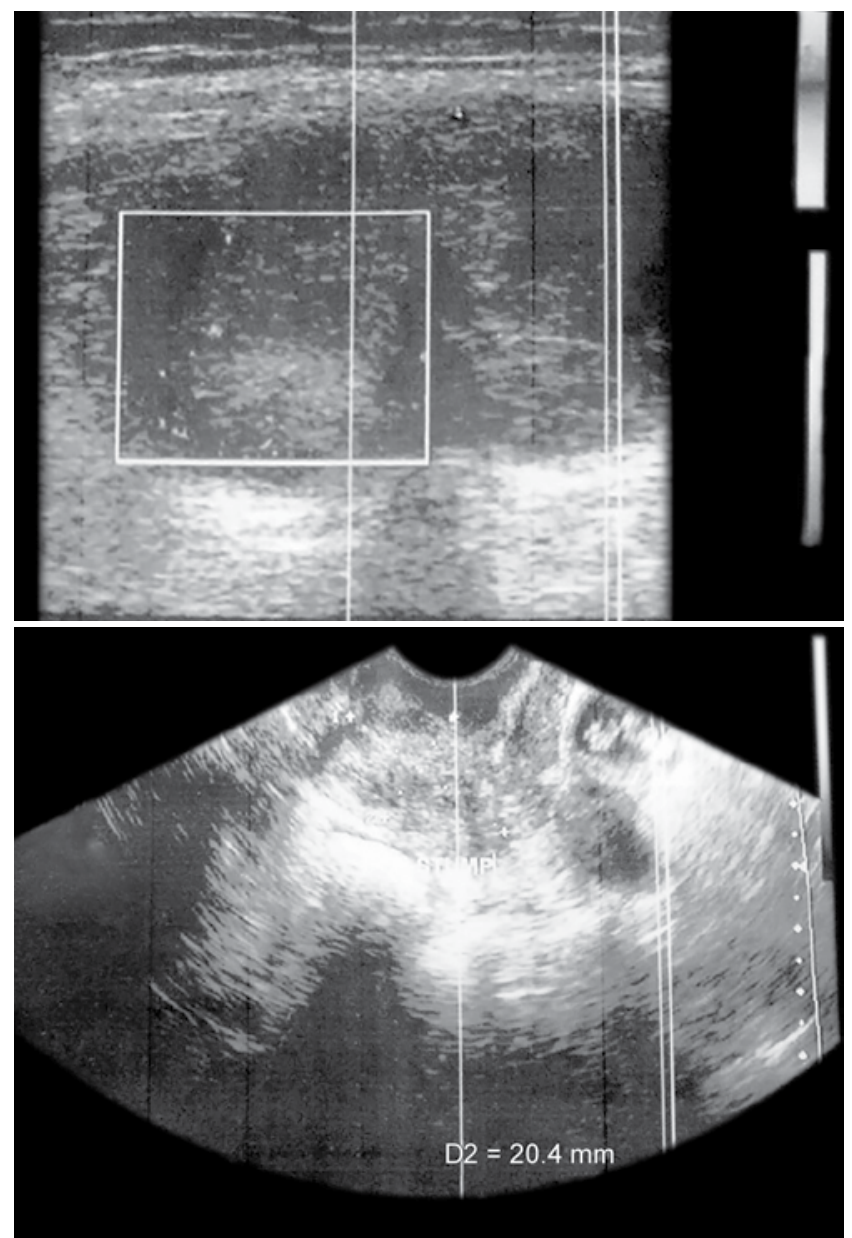

Fig. 1: USG displaying—scar implantation in abdominal wall and stump growth 


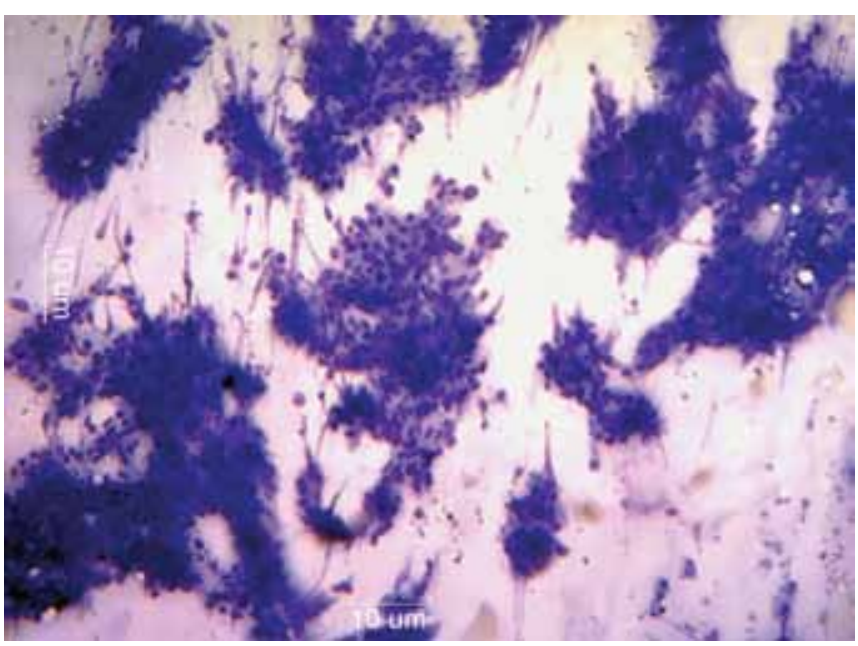

Fig. 2: FNAC from incisional site mass

between bladder and rectum, infiltrating bilateral parametrium. Also a large irregular mass $(3.9 \times 3.0 \times 2.7 \mathrm{~cm})$ noted in anterior abdominal wall in muscular plane with moderate to intense postcontrast enhancement, causing mild indentation over urinary bladder with no obvious invasion. Few enhancing peritoneal nodules also noted below the lesion (?) Neoplastic.

Ultrasonography-guided fine needle aspiration cytology (FNAC) from incisional site mass suggested positive cytology for malignant cells ( Favor Metastatic Squamous Cell Carcinoma) (Figs 2 and 3).

Patient was referred to radiotherapy but she succumbed to the disease in the middle of her treatment.

\section{DISCUSSION}

Common metastatic skin incisional cancers have been reported with cancers of colon, kidney and bladder. Although in developing countries, carcinoma cervix is the most common genital malignancy in women, cutaneous involvement originating from cervical cancer is particularly unusual, even in the terminal stage of the disease. ${ }^{1}$ It has been reported in few patients with adenocarcinoma and poorly differentiated histopathology, more so at drain site postoperatively. ${ }^{2}$

The frequency of skin metastasis with carcinoma cervix is estimated from 0.01 to $2 \%{ }^{3}$ The presence of metastasis suggests generalized dissemination of the disease and reflects a rapidly progressive disease in the final stage.

According to one study among patients of carcinoma uterine cervix, $1.3 \%$ developed skin metastases. The incidence of skin metastasis was $0.8 \%$ in stage I, $1.2 \%$ in stage II, $1.2 \%$ in stage III and $4.8 \%$ in stage IV. ${ }^{4}$ The interval between the diagnoses of cervical cancer and skin metastasis ranged from 0 to 69 months, with a mean of 16.9 months. The most common sites of skin lesions were

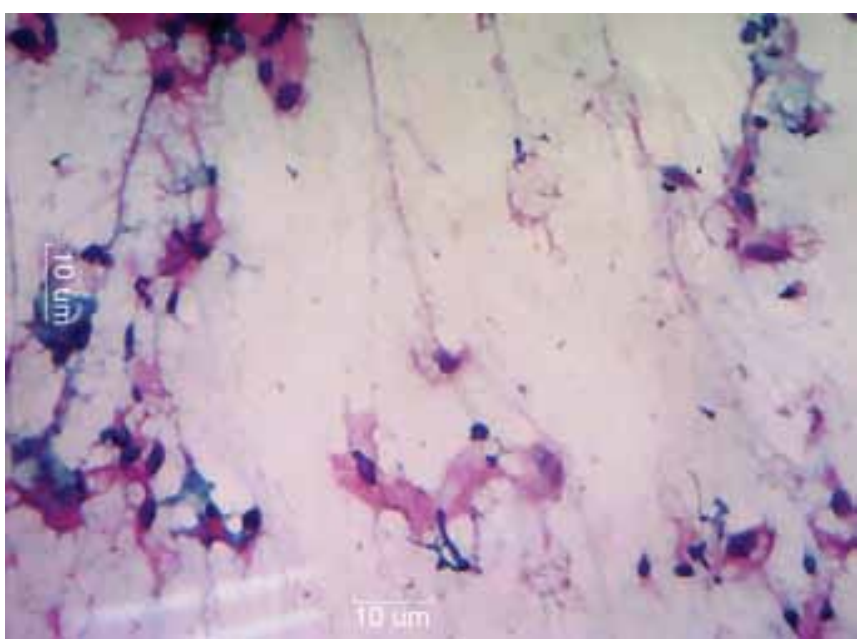

Fig. 3: FNAC from incisional site metastasis

the abdominal wall and vulva, followed by the anterior chest wall. Further, there have been reports of recurrence in the abdominal wall incision after hysterectomy in a diagnosed case of carcinoma cervix. ${ }^{5}$

This case was different because she never had any complaints of irregular or postcoital bleeding pv or foul discharge pv either before or after hysterectomy. Further, the rapid appearance and growth of incisional site mass postoperatively within 2 months of surgery, causing confusion with scar granuloma came out to be positive for metastatic squamous cell carcinoma.

Thus, skin metastasis can be an initial manifest lesion in few patients of carcinoma cervix with grave prognosis. Current review of literature suggests that the main treatment for these patients is extirpation of the skin lesion along with radiotherapy/chemotherapy.

\section{ACKNOWLEDGMENT}

The author acknowledges all junior co-authors for their support for which reporting of this case was possible although the patient despite being diagnosed in time could not be survived.

\section{REFERENCES}

1. Behtash N, Ghaemmaghami F, Yarandi F, Ardalan FA, Khanafshar N. Cutaneous metastasis from carcinoma of the cervix at the drain site. Gynecol Oncol 2002 Apr;85(1):209-211.

2. Srivastava K, Singh S, Srivastava M, Srivastava AN. Incisional skin metastasis of a squamous cell carcinoma 3.5 years after radical treatment-a case report. Int J Gynecol Cancer 2005 Nov-Dec;15(6):1183-1186.

3. Grabiec M, Walentowicz M, Marszalek A. Multiple skin metastases to vulva from carcinoma of the cervical stump. Ginekol Pol 2010 Feb;81(2):140-143.

4. Imachi M, Tsukamoto N, Kinoshita S, Nakano H. Skin metastasis from carcinoma of the uterine cervix. Gynecol Oncol 1993 Mar;48(3):349-354.

5. Sharma DN, Chawla S, Chander S, Gairola M, Thulkar S, Singh MK. Cervical carcinoma recurring in an abdominal wall incision. Clin Oncol (R Coll Radiol) 2000;12(6):354-356. 